\title{
The Role of a Medicalized Discourse in the Global Activities of the World Health Organization
}

\begin{abstract}
This article presents selected results of a research project entitled Medicalization Strategies of the World Health Organization ${ }^{1}$ in which the author analyzed and described three WHO policies characterized by a medicalizing approach. These three policies were compared with each other in terms of their conceptual (narrative) and institutional (practical) levels of medicalization and their effects. In order to better understand the role of a medicalized discourse in the global activities of the WHO, these three cases were also compared to one non-medicalizing policy. The aim of this article is twofold: firstly, to present two cases analyzed as part of the project, namely, the tobacco policy (a 'medicalized' one) and the ageing policy (a 'non-medicalized' one) and secondly, to consider the possible influence of WHO discourse on tobacco and ageing on public health policies in the European Union.
\end{abstract}

Keywords: medicalization, epistemic communities, tobacco, ageing, constructivism

\section{Introduction}

The concept of medicalization means 'making something medical' and dates back to the 1960s when scholars such as Irving Zola, Ronald Laing and Thomas Szasz observed that medicine was no longer a socially-neutral body of knowledge regarding the treatment of various health problems, but had became a powerful institution of social control (Conrad, 1992, pp. 209-210). Interestingly, the rise

The project has been funded by the National Science Centre, Poland (grant no. 2017/25/N/ HS5/00950). 
of the concept coincided with the so called 'anti-psychiatric movement', which was led by former psychiatrists who were dissatisfied with oppressive and brutal ways of dealing with mental health problems such as psychoses, schizophrenias and depression (Conrad, 2013, pp. 195-197; Zola, 1973). They claimed that medicalization was a feature of modernity and simply aimed at increasing the role of doctors within Western societies (Ballard, Elston, 2005). Although some scholars still associate medicalization with the economic expansion of the pharmaceutical industry (Clarke, Shim, Mamo et al., 2003, pp. 168-171; Williams, Calnan, 1996), in the vast majority of sociological studies the term is used in a neutral sense, as a concept that describes a perceived social process objectively (Conrad, 2005, p. 7; Searight, McLaren, 1998; Tournier, 1985; Boero, 2007, pp. 43-58).

I decided to make use of the concept of medicalization outside sociology and apply it to the discipline of International Relations. The primary and somehow 'natural' body that could be investigated in terms of how it employs medicalizing discourse was the World Health Organization, a specialized UN agency which is the only international organization that operates in the field of health, bringing together 194 countries. Therefore, the main research question was: what is the role of medicalization in WHO's international activities? I assumed that medicalization, together with such processes as securitization and financialization, could be a powerful instrument for influencing global approaches to different problems (Stritzel, 2007; Buzan, Wæver, de Wilde, 1998; van der Zwan, 2014). I hypothesized that medicalization allowed WHO to direct countries' attention towards health problems which otherwise would have been ignored. The important rationale behind this hypothesis was that the World Health Organization is consistently and severely underfinanced, and the budget allocated to NonCommunicable Diseases cannot be compared to the resources spent on the fight against infectious diseases (Horton, 2002; Godlee, 1994; van de Pas, van Schaik, 2014).

\section{Theoretical background and methodology}

As has been mentioned, this research project is based on the concept of medicalization. According to Peter Conrad, a leading specialist in this field, it is a process by which some human problems are conceptualized and treated as diseases and resolved by using pharmaceuticals (Conrad, 1992, p. 210). He distinguishes three levels of medicalization, namely, conceptual, institutional and interactional (Conrad, Schneider, 1980, p. 75). The conceptual level of medicalization means that a society starts to think and speak about a problem as if it were a disease or medical condition (Conrad, 1992, p. 210). New medical labels are emerging and 
problems, human features and even life events are being perceived as syndromes or health problems, as in the case of shyness, obesity and - to a lesser extent ageing. The institutional level of medicalization focuses on practices and activities which legitimize medicalized discourse on a problem (Conrad, 1992, p. 211). New highly-specialized clinics, medical institutions and medical specializations are being developed in order to manage and treat problems which were not defined as illnesses a few centuries ago, as in the case of alcoholism (Valverde, 1997, pp. 251-253; Saguy, Riley, 2005). The last level of medicalization, namely, the interactional one, focuses on the process of becoming a patient during individual interactions between a doctor and a sick person (Conrad, 1992, p. 211).

Bearing in mind the fact that this study concerns an international organization, the only levels of medicalization that can be analyzed are the conceptual and institutional ones. The first one is defined as all the discursive and narrative tools included in WHO's official publications which create a medicalized construct, that is, which endows a problem with the features of a disease. These features are based on Talcott Parsons's classic concept of the role of the sick in society and includes the observations that a disease leads to death if not treated properly, a sick person is not responsible for his/her illness, a sick person cannot perform his/her daily activities due to the illness and needs help from others, and that a sick person should look for proper treatment if (s)he wants to be healthy again (Parsons, 1975). The second, institutional, level of medicalization has been defined as all the projects, programmes and initiatives organized by the WHO which reproduce a medicalized concept and make the concept 'work' in practice. Therefore, I collected information about WHO-led activities which had been prepared by specific departments and published on their official websites or in WHO's Institutional Repository for Information Sharing (WHO IRIS).

As one can observe, this study is grounded in a constructivist paradigm in International Relations that assumes, firstly, that norms, rules and values are crucial in shaping the global agenda of problems (Adler, 2013, p. 113; Haas, 2006, pp. 442-443). Secondly, the international reality is always dynamic and is continuously being shaped by human activity. Therefore, it is agency, rather than agent/structure dilemmas, which they pay attention to (Hopf, 1998, pp. 177180). Thirdly, international actors behave and act according to the so-called 'logic of appropriateness' (Checkel, 1997, pp. 474-480; 1998, p. 326). The fourth assumption concerns intersubjectivity in the analysis of global politics (Adler, 2013, pp. 121-122; Finnemore, Sikkink, 2001, p. 395). An important term which was useful during the analysis was 'epistemic community'. An epistemic community is a group of experts and/or scientists that come together as a more or less formalized body that aims to resolve a transboundary problem (Haas, 1992, pp. 3-7). The term is based on Karl Deutsch's idea of 'security communities' and was introduced by the neofunctionalist Ernst Haas and developed by Peter Haas, who used it when describing how experts change the context of some vital 
global issues, such as global warming and the protection of sea resources (Haas, 1989, pp. 392-393; Haas, 1990, pp. 348-349). Observing the World Health Organization through the lens of the epistemic community approach led me to the conclusion that the WHO is a label for many internally differentiated epistemic communities of experts who are working in various specialized departments on solutions which may influence real changes in international relations.

In order to complete the methodological picture sketched above, it is necessary to describe the practical steps which led me to the conclusions presented in the following sections. The main research method was comparative analysis (Ragin, 1998, 2014; Rihoux, 2006; Rihoux, Ragin, 2008) and the two cases which were chosen concern the tobacco and ageing policies of the WHO. The tobacco policy was chosen because it has resulted in one of the most impressive achievements in WHO history, that is, the Framework Convention on Tobacco Control, whereas the ageing policy was included in the study since it is not characterized by medicalization. Both policies concern important public health challenges, but the epistemic communities' approaches towards them are quite different.

The conceptual level of medicalization was studied with the aid of discourse analysis supported by the software package MaxQda 2018.2. The documents included official publications of each epistemic community of the WHO (published between 1980 and 2019) and were divided into two categories, namely, legal acts and technical documents. In order to check the efficacy of each discursive construct, this study also includes an analysis of official documents prepared by the European Commission and the European Parliament which concern tobacco and ageing. All the documents were coded using the variable 'Subject' (values: Economy; Science; Medicine; Public Health; Law and Security). The inclusion/exclusion criteria are presented in Appendix 1. The basic unit for coding fragments is the paragraph. One fragment could have been coded with more than one code. The exact number of codes used is summarized in Appendix 2. Only materials in English were analyzed and they were gathered from the WHO IRIS database. I searched for publications that had the following categories as their subject: "tobacco", "smoking", "FCTC", "ageing", "aging" and "the elderly". The final selection of materials prepared by the WHO epistemic communities included 38 legal acts and 63 technical publications on tobacco, compared to 16 legal acts and 25 technical publications on ageing. The final selection of the EU documents included 25 publications on tobacco and 21 publications on ageing prepared by the European Commission and one publication on tobacco and two publications on ageing published by the European Parliament.

In order to describe institutional medicalization, I carefully reviewed official WHO articles, materials, guidelines on its official website as well as documents from the WHO IRIS database published between 1980 and 2018. The efficacy of each construct was understood as the correspondence between the WHO and the EU discourses on tobacco and ageing as well as the level of implementation of WHO epistemic communities' ideas on public health policy within the EU. 


\section{The tobacco 'success story' of the WHO}

\section{The WHO construct}

The anti-tobacco epistemic community brings together a number of experts and scientists who work for the WHO or collaborate with the Organization to combat the so called 'smoking epidemic' (WHO, 2018a, 2019a, 2019b). This idea means that the scope of tobacco-related diseases, especially cancers, is so huge that, according to the experts, it has achieved pandemic proportions. In order to make this message more clear, the epistemic community quite often refers to mortality statistics that prove that the exact number of victims of the pandemic has reached millions. What is more, smokers are not responsible for their 'illness', since it is the tobacco industry that continues to sell a potentially dangerous and addictive product, namely, nicotine. This approach explains why the epistemic community of WHO experts has put so much effort into banning tobacco marketing. Another important feature of the WHO discursive construct is the ability to combine medicalized language on smoking with security and economy. In particular, this is underlined while portraying the dangerous and potentially lethal properties of nicotine (security frame) and other substances which are present in cigarettes and tobacco products (economic frame) and inhaled by smokers (WHO, 2004, 2008, 2009, 2012). Here, the medicalization of smoking has helped the anti-tobacco experts to convince Ministers of Health as well as Ministers of Finance of WHO Member States that banning tobacco in public places is not only a question of convenience for non-smokers, but also a question of safety. An analysis of WHO discourse in the official materials of the antitobacco epistemic community also confirms these observations, since the most frequently used codes are 'Medicine, 'Public Health', 'Security' and 'Economy' with slight differences in their order between the legal and technical documents, which is presented below.

\section{The EU construct}

Taking into account the language of documents and materials prepared by the European Commission, it seems that EU discourse on tobacco shares some similarities with the WHO construct. Firstly, the use of the category 'Medicine' means that emphasizing the mortality caused by tobacco is still one of the most important factors in attracting the attention of EU Member States. However, terms such as 'tobacco pandemic' or 'smoking epidemic' are rarely used by EU experts. It cannot be denied that they prefer to talk about 'the health hazards of smoking' or 'health problems caused by tobacco', which results in the codes 'Public Health' and 'Security' codes occurring together quite frequently within the materials analyzed. Secondly, EU experts have also paid quite a lot of attention to the tobacco 


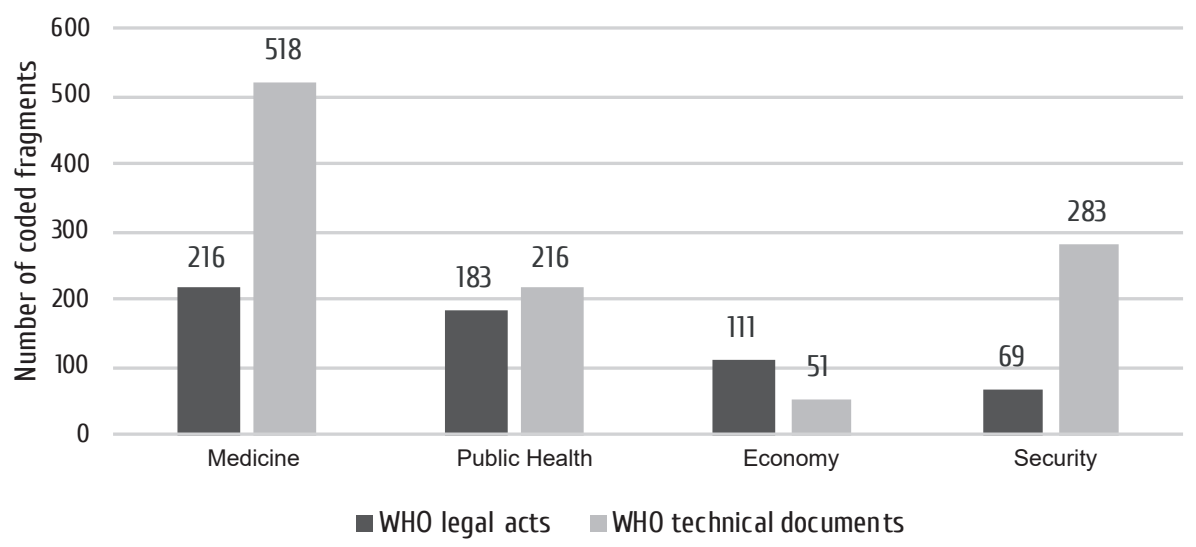

Fig. 1. A comparison of the frequency of the codes selected between legal and technical publications of the WHO anti-tabacco epistemic community

companies which are responsible for the aggressive marketing of tobacco products, but they call them 'tobacco manufacturers' instead of the 'tobacco industry', which is a more neutral way of labelling their activities on the tobacco market. Thirdly, the code 'Security' is the most frequent one within the materials analyzed, which means, on the one hand, that medicalization can be a powerful tool for creating new health hazards, but on the other, that medical labels cannot be effective by themselves, simply because they do not attract the attention of the general public to the same extent as in the case of health experts. Generally, the discourse of the European Commission's documents presents a more neutral and balanced stance towards the 'tobacco epidemic' than the official publications of the WHO, but they still contain some features of medicalized narratives on smoking. A summary of the codes used is presented below.

\section{Effects}

On the global level, the institutional level of the medicalization of smoking is aimed at popularizing the idea of a 'tobacco epidemic' and convincing governments to establish anti-tobacco policies. The main tools of such a policy are the WHO Tobacco Free Initiative (TFI) and the Framework Convention on Tobacco Control (FCTC). The TFI was established in 1998 by WHO Director General, Gro Harlem Brundtland, and includes a combination of scientific, security and economic measures which are intended to lead to the elimination of tobacco products from global markets and the public sphere. Within the TFI framework, the anti-tobacco epistemic community prepares reports and shares 


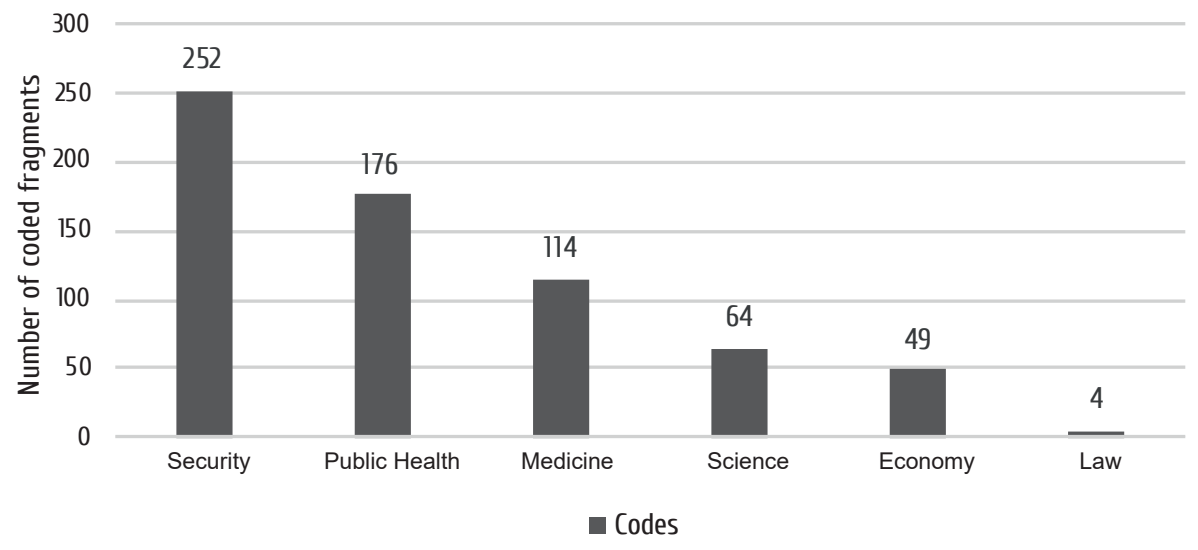

Fig. 2. The distribution of codes within the documents of the European Commission

data on the mortality and morbidity which are caused by tobacco (WHO, 2018a, 2019a). The Framework Convention on Tobacco Control was and still is the first and only global public health treaty negotiated under the auspices of the WHO. The FCTC came into force in 2005 and includes almost all spheres covered by the endeavours of the TFI, and has added new ones. It gives the anti-tobacco epistemic community a legal tool for controlling prices, taxes [art. 6], and the packaging of cigarettes [art. 11] as well as for monitoring smoking via the idea of smoke-free environments [art. 8, art. 18]. The FCTC requires the price of cigarettes to increase [art. 6], smoking areas in public places to be provided [art. 8], the design of cigarette packages to be monitored [art. 11] and requires packages to be labeled with health warnings [art. 11 and 13]. The rates of implementation of these FCTC articles indicate that the anti-tobacco policy of the WHO can be called a success.

The anti-tobacco policy within the EU follows the steps initiated by the epistemic community of the WHO. Firstly, the assumption that it is the tobacco manufacturer, not the smoker, that should be punished for selling a dangerous product, is still present in encouraging the EU Member States to take tobacco-control measures such as the regulation of tobacco packaging, tax measures, restrictions on tobacco advertising and creating smoke-free environments (European Parliament, 2014). The Tobacco Products Directive, which regulates the visibility of health warnings on tobacco packages, has been actively implemented since 2014 . Moreover, it has also established a European base of health warnings which can be used by tobacco companies on the common market (European Commission, 2014). It is worth mentioning that implementation rates of the FCTC within the 


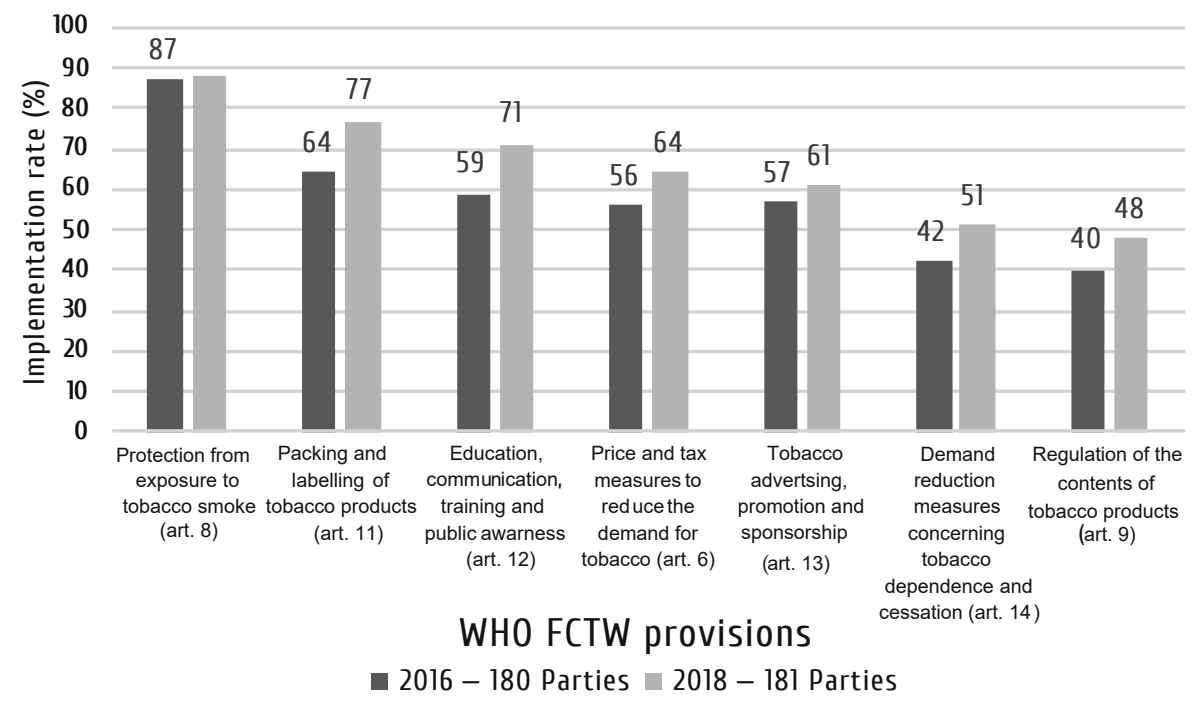

Fig. 3. Average implemantation rates (\%) of chosen FCTC articles by Parties Based on: WHO 2018 Global Progress Report on Implementation of the WHO Framework Convention on Tobacco Control, Geneva 2018.

WHO European Region are very high and many EU Member States participate in the Joint Action on Tobacco Control, which supports the parties of the FCTC in fulfilling their obligations effectively. In this sense, the medicalized 'tobacco epidemic' construct has been a huge success of the anti-tobacco epistemic community, even if the label is not so frequent in documents prepared by the European Commission.

\section{The ageing policy: A challenge for the WHO}

\section{The WHO construct}

Unlike the former case, the WHO epistemic community on ageing does not apply the medicalized approach. The main idea regarding managing the challenge of the 'greying of nations' relies on the Healthy/Active Ageing approach, which means that the elderly should actively participate in social activities, which they used to do before retirement, and stay independent from family carers. Therefore, the main aim of the Healthy Ageing idea is to weaken the elderly's dependency on medical institutions and pharmacological solutions. Consequently, the WHO epistemic community on ageing employs another narrative approach which is called healthism (Crawford, 1980; Kirk, Colquhoun, 1989), since at the core of their discourse on ageing is the category of health, not disease. The main 


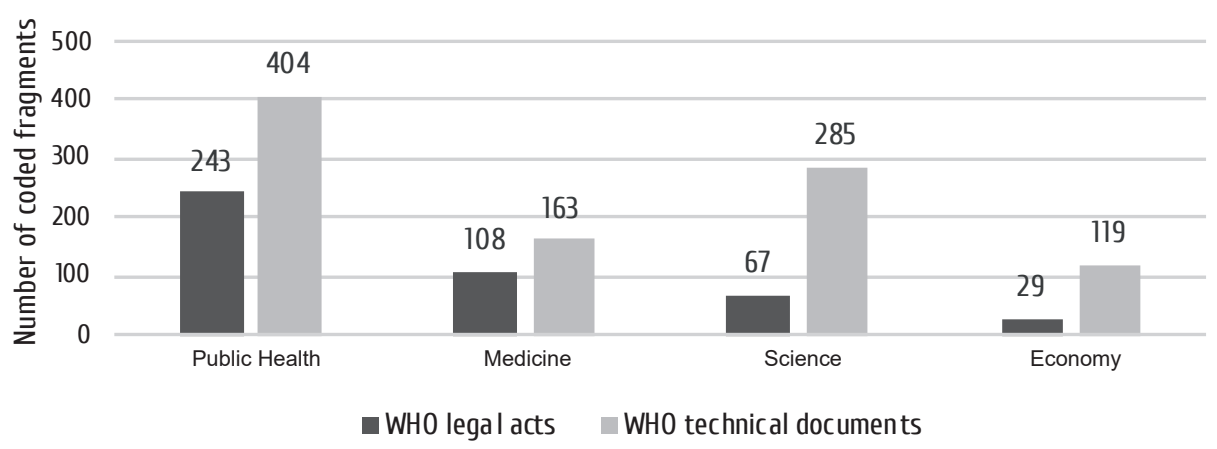

Fig. 4. A comparison of the frequency of the codes selected between legal and technical publications of the WHO epistemic community on ageing

characteristic feature of this approach is the fact that it concentrates on public health measures such as social campaigns and workshops which promote physical and social activity among the elderly. Thus, the materials prepared by the WHO epistemic community contain 'staying healthy' labels. The only 'medicalized' sector of the WHO ageing policy is the one that focuses on ageing-related comorbidities such as dementia. Such materials include many medical terms, but overall, the number of these documents is not very high. Interestingly, the WHO epistemic community has conducted many research projects on the biological mechanisms of ageing and on technological innovations that support the functioning of the elderly, which explains the relatively high frequency of the code 'Science' within these materials. Discourse on ageing, especially within the technical documents of the WHO, also includes the frame 'Economy', since maintaining activity and productivity after retirement is considered to have a good impact on the health of older people The distribution of these codes within the legal and technical documents of the WHO epistemic community is summarized in the figure below.

\section{The EU construct}

The documents prepared by the European Commission are characterized by a similar set of codes that are used in mapping the discourse of the WHO epistemic community, that is, 'Medicine, 'Public Health' and 'Economy'. The main difference between them is that the EU documents focus, above all, on the medical aspect of ageing, namely on the effective managing of illnesses in the elderly. Thus, the EU construct seems to be significantly more medicalized than the WHO one, which is not in line with the official policy of the epistemic 
community. This fact can be partially explained by an important characteristic of medicalization, which is the circumstance that they make problems more operational and manageable. Therefore, it is easier to construct indicators of medical conditions in the elderly such as dementia or chronic obstructive pulmonary disease than of their wellbeing. In addition, compared to the WHO construct on ageing, the EU construct strongly relies on the economic component. It means that EU policymakers are more eager to see the elderly through the lens of their retirement and loss of productivity than their WHO counterparts. Generally, the frequency of the codes selected within the EC documents indicates that the idea of Healthy/Active Ageing does not bring the expected results as far as the change in how the elderly are perceived throughout the world is concerned.

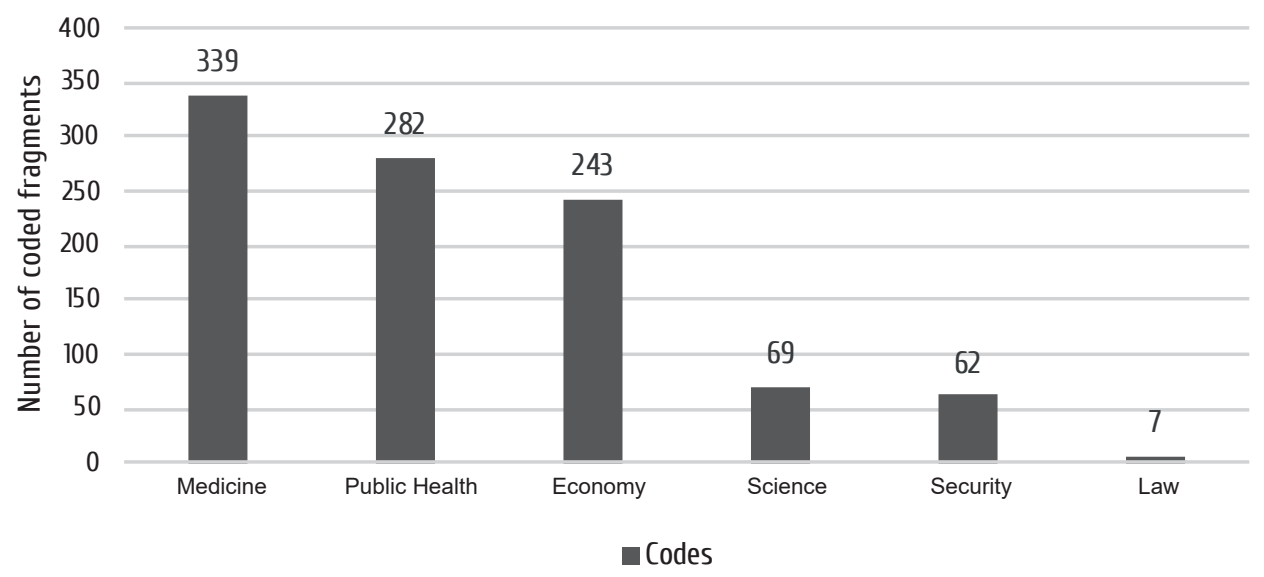

Fig 5. The distribution of codes within the documents of the European Commission

\section{Effects}

It seems that the most important project that applies the non-medical point of view on ageing policy was the Age-Friendly Cities Initiative established in 2010, which encourages cities to modify their urban space in order to make it more available to the needs of the elderly (WHO, 2018b, 2019c). Another project was the WHO Guidelines on Integrated Care for Older People (ICOPE) introduced in 2017, which was directed at caregivers and families of the elderly who are not independent (WHO, 2017). The problem is that on a global level the attention directed at the very serious problem of ageing societies is quite poor compared to the tobacco case. Only $58 \%$ of WHO Member States have established a focal point on ageing, while the existence of an anti-discriminatory law that protects 
the elderly has been declared by only $45 \%$ of countries (WHO, 2017). More than half of the countries could not declare age-friendly environments, even in European and American WHO regions (WHO, 2017).

Within the EU, the majority of efforts that focus on ageing are led by the European Innovation Partnership on Active and Healthy Ageing, which is divided into six Action Groups dealing with different aspects of ageing, while three of them (Lifespan Health Promotion, Independent living solutions and Age friendly environments) are directly related to the WHO construct. This platform brings together scholars, scientists, health care organizations and patients' associations (EIP, 2020). The Action Groups focus especially on the prevention and management of frailty in the elderly, promoting the active participation of older people in social life and building partnerships, with the majority of projects aiming at dealing with health problems in the elderly rather than at workshops that develop their abilities (EIP, 2016a; EIP, 2016b). This does not mean that the ageing policy of the WHO has failed, however. This case points to some crucial problems posed by the fact that there are some phenomena that cannot be medicalized. Apart from anti-ageing ideas, growing old has always been perceived as a life-course process that cannot be labelled as a disease itself. Medicalizing ageing could possibly mean underlining diseases in the elderly, but it would not have fit into the scheme of healthy and independent elderly people. Instead, the members of the epistemic community prefer to strengthen the capabilities of the elderly and, therefore, focus on the category of health, rather than disease.

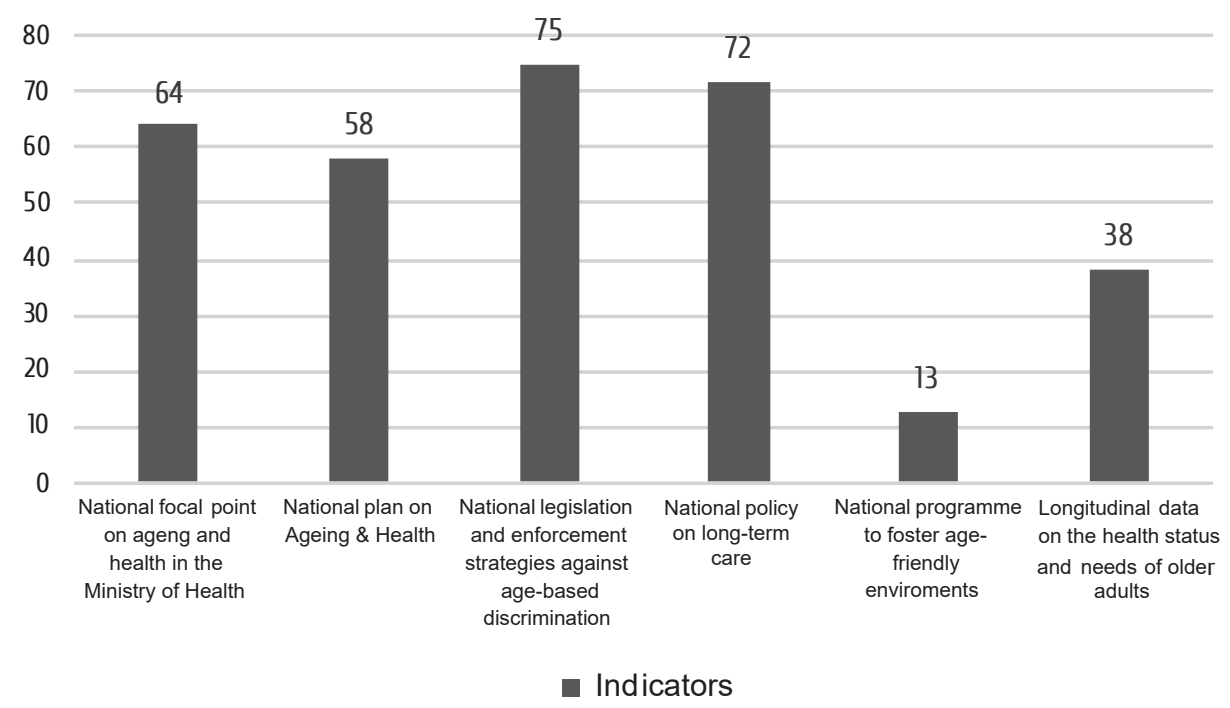

Fig. 6. Selected indicators of Healthy Ageing policies within WHO European Regional Office Based on: WHO Global Strategy and Action Plan on Ageing and Health. 10 Mid-Term Progress Indicators, Geneva 2018. 


\section{The role of a medicalized discourse: A comparison of the two}

\section{cases}

Careful analysis of these cases leads us to the conclusion that medicalization can be a powerful tool for directing global attention towards Non-Communicable Diseases. Firstly, because it has helped epistemic communities to formulate the problem in a more operationalized way. This means that medical labels and the involvement of doctors somehow distinguish one phenomenon from many others and mobilize human and financial resources in order to solve it, as we could see in the tobacco case. As could be seen, some traces of such a logic are visible in the EU documents on ageing, where the problem seems to be more manageable than in the case of the health-oriented approach of the WHO. Secondly, medicalization creates a social necessity to act, since no kind of prevention strategy is less appealing to the public than the feeling of insecurity that diseases cause. Whereas the label 'tobacco epidemic' is not so frequently repeated in the EU documents, solutions proposed by the EU policymakers strictly follow the orientation presented in the FCTC. Compared to this, the healthist discourse of the WHO epistemic community does not have a similar effect and the fact that the EU documents describe a far more medicalized construct only confirms this observation. Thirdly, medicalization fosters measurability of the solutions implemented in terms of decreased mortality and morbidity, which can also be appealing to potential stakeholders. Unlike in the tobacco case, the challenge of ageing societies cannot be based only on the idea of a life-course

Table 1. A comparison of the cases analyzed

\begin{tabular}{|c|c|c|}
\hline & TOBACCO CASE & AGEING CASE \\
\hline The main problem & Tobacco. & $\begin{array}{l}\text { Health problems in the aged leading to } \\
\text { social dependence. }\end{array}$ \\
\hline $\begin{array}{l}\text { Conceptual } \\
\text { medicalization: } \\
\text { basic assumptions }\end{array}$ & $\begin{array}{l}\text { Tobacco-related diseases are a growing epidemic } \\
\text { throughout the world. }\end{array}$ & Not applicable. \\
\hline $\begin{array}{l}\text { Conceptual } \\
\text { medicalization: } \\
\text { epistemic } \\
\text { communities' } \\
\text { official discourse }\end{array}$ & $\begin{array}{l}\text { Frequent presence of the categories 'Medical', } \\
\text { 'Security' and 'Public health'. Economic categories } \\
\text { are also applied. }\end{array}$ & $\begin{array}{l}\text { Frequent presence of the categories 'Public } \\
\text { health' and 'Scientific'. Medical codes are } \\
\text { frequently used in publications on } \\
\text { dementia. }\end{array}$ \\
\hline $\begin{array}{l}\text { Institutional } \\
\text { medicalization: }\end{array}$ & $\begin{array}{l}\text { Apart from health warnings, medical solutions } \\
\text { supporting giving up tobacco addiction are part of } \\
\text { TFI and FCTC proposals, whereas other solutions } \\
\text { are of an economic and financial nature. }\end{array}$ & $\begin{array}{l}\text { Not applicable. Rather WHO initiatives are } \\
\text { aimed at 'demedicalizing' ageing, } \\
\text { understood as making the elderly } \\
\text { independent of medical institutions. }\end{array}$ \\
\hline $\begin{array}{l}\text { Functions } \\
\text { performed by the } \\
\text { WHO (articles in } \\
\text { WHO Constitution) }\end{array}$ & $\begin{array}{l}\text { Art. } 2(a), 2 b, 2 d, 2 f, 2 g, 2 j, 2 k, 2 n, 2 q, 2 r, 2 u(11 \\
\text { functions). }\end{array}$ & $\begin{array}{l}2 \mathrm{a}, 2 \mathrm{~b}, 2 \mathrm{c}, 2 \mathrm{~d}, 2 \mathrm{f}, 2 \mathrm{i}, 2 \mathrm{j}, 2 \mathrm{l}, 2 \mathrm{n}, 2 \mathrm{p}, 2 \mathrm{q}, 2 \mathrm{r} \\
\text { (12 functions). }\end{array}$ \\
\hline
\end{tabular}


approach. Although it accentuates the necessity of physical exercise, a healthy diet and the avoidance of tobacco, the addressees of the message are too general. This explains why the European Commission and the EIP have not given so much attention to the life-course approach, focusing on health problems in the elderly instead. Finally, medicalization can allow many WHO constitutional functions to be fulfiled, which is summarized in the table below. It is also worth mentioning that between 2014 and 2016 resources allocated to tobacco policy, which is divided into the categories 'Risk factors' and 'Tobacco legislation', oscillated around 19.6 million euro compared to 12.2 million allocated to the category 'Active and Healthy Ageing' (European Commission, 2017, p. 16).

\section{Discussion}

As we have seen, medicalization has strong potential to be an effective tool in attracting stakeholders' attention. As we know, the World Health Organization has very limited resources, especially in noncommunicable diseases, and the dynamics of policies in this sphere are almost entirely dependent on extra-budgetary funds (Godlee, 1994). Therefore, the medicalization of discourse on a chosen problem could be an interesting way of changing global approaches towards challenges which otherwise would have gone unnoticed. Nevertheless, this study has some vital limitations. First of all, it is not representative of all the WHO departments and, thus, medicalization cannot be treated as a general rule in managing global health problems. Secondly, this study lacks an analysis of the internal discourse used by the members of the EIP, which would have told us more about the real stance of EU policymakers regarding ageing. The main subject of this analysis is the correspondence between the language of the official publications of the WHO epistemic community and those of the EU, but there is no evidence regarding the extent to which the WHO documents inspire the authors of the EU documents. In the case of anti-tobacco policy, an important indicator is the fact that the EU Member States are still implementing the FCTC articles, which would not have been possible if it were not for the medicalization of smoking. Thirdly, as in the case of other qualitative studies, this analysis lacks reliability, which means that the categories used as well as inclusion/exclusion criteria may differ depending on the theoretical background of the researcher. Finally, this study does not intend to present medicalization as a somehow 'preferred' option for WHO experts. It only focuses on describing the mechanisms observed in the policies selected. Furthermore, the work of other actors, such as patients' movements and NGOs which support WHO's epistemic communities, also possibly play a vital role in the process, which needs to be studied further. 


\section{Conclusion}

Bearing in mind some limitations of which I am aware, this study has answered the question regarding the role of medicalization in the international activities of the WHO. As could be observed in the case of ageing policy, this problem is not obvious, because the fact that the World Health Organization is a global agency that specializes in the field of health does not determine the medical labelling of every health problem it deals with. The use of medicalized discourse is highly dependent on a normative environment. This means that it is possible only when the global and local partners of an epistemic community take scientific knowledge seriously and respect solutions that rely on it, just as in the case of Mediterranean ecological resources (Haas, 1990). Nevertheless, if used, 'making things medical' can produce positive effects when it comes to strengthening the position of the World Health Organization as a global health authority, especially regarding its work in the underfinanced field of Non-Communicable Diseases.

\section{References}

Adler, E. (2013). "Constructivism in International Relations: Sources, Contributions, and Debates". In: W. Carlsnaes, T. Risse, B. Simmons (eds.). Handbook of International Relations. London: Sage Publications, pp. 112-144.

Ballard, K., Elston, M.A. (2005). "Medicalisation: A Multi-dimensional Concept". Social Theory \& Health 3(3), pp. 228-241.

Boero, N. (2007). "All the News That's Fat to Print: The American 'Obesity Epidemic' and the Media". Qualitative Sociology 30(1), pp. 41-60.

Buzan, B., Wæver, O., de Wilde, J. (1998). Security: A New Framework for Analysis. London: Lynne Rienner Publishers.

Checkel, J.T. (1997). "International Norms and Domestic Politics: Bridging the Rationalist - Constructivist Divide". European Journal of International Relations, 3(4), pp. 473-495.

Checkel, J.T. (1998). “The Constructive Turn in International Relations Theory”. World Politics, 50(2), pp. 324-348.

Clarke, A.E., Shim, J.K., Mamo, L. et al. (2003). "Biomedicalization: Technoscientific Transformations of Health, Illness, and US Biomedicine". American Sociological Review, 68(2), pp. 161-194.

Conrad, P. (1992). "Medicalization and Social Control". Annual Review of Sociology, 18(1), pp. 210-211.

Conrad, P., Schneider, J.W. (1980). "Looking at Levels of Medicalization: A Comment on Strong's Critique of the Thesis of Medical Imperialism". Social Science \& Medicine. Part A: Medical Psychology \& Medical Sociology, 14(1), pp. 75-79.

Conrad, P. (2005). "The Shifting Engines of Medicalization". Journal of Health and Social Behavior, 46(1), pp. 3-14. 
Conrad, P. (2013). "Medicalization: Changing Contours, Characteristics, and Contexts". In: W. Cockerham (ed.). Medical Sociology on the Move. Dodrecht: Springer, pp. 195-214.

Crawford, R. (1980). "Healthism and the Medicalization of Everyday Life". International Journal of Health Services, 10(3), pp. 365-388.

EIP (2016a). European Innovation Partnership on Active and Healthy Ageing. Action Group C2 - 2016-2018, https://ec.europa.eu/eip/ageing/actiongroup/index/c2/key-documents_en (accessed: 2.09.2020).

EIP (2016b). European Innovation Partnership on Active and Healthy Ageing. Action Group D4 - 2016-2018, https:/ec.europa.eu/eip/ageing/actiongroup/index/d4/ key-documents_en (accessed: 2.09.2020).

EIP (2020). What Is the European Innovation Partnership on Active and Healthy Agei$n g$ (EIP on AHA)?, https://ec.europa.eu/eip/ageing/about-the-partnership_en (accessed: 2.09 .2020$)$.

European Commission (2014). Commission delegated Directive 2014/109/EU of 10 October 2014 amending Annex II to Directive 2014/40/EU of the European Parliament and of the Council by establishing the library of picture warnings to be used on tobacco product, https://eur-lex.europa.eu/legal-content/EN/TXT/PDF/?uri=CELEX :32014L0109\&from=EN (accessed: 2.09.2020).

European Commission (2017). Mid-term Evaluation of the third Health Programme (2014-2020). Final report, https://ec.europa.eu/health/funding/programme/ 2014-2020/midterm_evaluation_pl (accessed: 2.09.2020).

European Parliament (2014). Directive 2014/40/EU of the European Parliament and of the Council of 3 April 2014 on the approximation of the laws, regulations and administrative provisions of the Member States concerning the manufacture, presentation and sale of tobacco and related products and repealing Directive 2001/37/EC, https://ec.europa.eu/health/sites/health/files/tobacco/docs/dir_201440_en.pdf (accessed: 2.09.2020).

Finnemore, M., Sikkink, K. (2001). “Taking Stock: The Constructivist Research Program in International Relations and Comparative Politics". Annual Review of Political Science, 4(1), pp. 391-416.

Godlee, F. (1994). "WHO in Crisis". British Medical Journal, 309(6966), pp. 1424-1428.

Haas, E.B. (1990). When Knowledge Is Power: Three Models of Change in International Organizations. Berkeley: University of California Press.

Haas, E.B. (2006). “Does Constructivism Subsume Neofunctionalism?”. In: M. Eilstrup-Sangiovanni (ed.). Debates on European Integration: A Reader. Hampshire: Palgrave Macmillan, pp. 437-445.

Haas, P.M. (1989). "Do Regimes Matter? Epistemic Communities and Mediterranean Pollution Control”. International Organization, 43(3), pp. 377-403.

Haas, P.M. (1992). "Introduction: Epistemic Communities and International Policy Coordination”. International Organization, 46(1), pp. 1-35.

Hopf, T. (1998). “The Promise of Constructivism in International Relations Theory”. International Security, 23(1), pp. 171-200.

Horton, R. (2002). "WHO Leadership: A Swift Start but with Few Clear Objectives". The Lancet, 360(9336), pp. 812-813. 
Kirk, D., Colquhoun, D. (1989). "Healthism and Physical Education”. British Journal of Sociology of Education 10(4), pp. 417-434.

Parsons, T. (1975). “The Sick Role and the Role of the Physician Reconsidered”. The Milbank Memorial Fund Quarterly. Health and Society, 53(3), pp. 257-278.

Ragin, C.C. (1998). "The Logic of Qualitative Comparative Analysis". International Review of Social History, 43(S6), pp. 105-124.

Ragin, C.C. (2014). The Comparative Method: Moving beyond Qualitative and Quantitative Strategies. Oakland: University of California Press.

Rihoux, B. (2006). "Qualitative Comparative Analysis (QCA) and Related Systematic Comparative Methods: Recent Advances and Remaining Challenges for Social Science Research". International Sociology, 21(5), pp. 679-706.

Rihoux, B., Ragin, C.C. (2008). Configurational Comparative Methods: Qualitative Comparative Analysis (QCA) and Related Techniques. Los Angeles: Sage Publications.

Saguy, A.C., Riley, K.W. (2005). "Weighing Both Sides: Morality, Mortality, and Framing Contests over Obesity". Journal of Health Politics, Policy and Law, 30(5), pp. 869921.

Searight, H.R., McLaren A.L. (1998). "Attention-Deficit Hyperactivity Disorder: The Medicalization of Misbehavior". Journal of Clinical Psychology in Medical Settings, 5(4), pp. 467-490.

Stritzel, H. (2007). "Towards a Theory of Securitization: Copenhagen and beyond". European Journal of International Relations, 13(3), pp. 357-383.

Tournier, R.E. (1985). “The Medicalization of Alcoholism: Discontinuities in Ideologies of Deviance”. Journal of Drug Issues, 15(1), pp. 39-49.

Valverde, M. (1997). "Slavery from within': The Invention of Alcoholism and the Question of Free Will”. Social History, 22(3), pp. 251-268.

Van de Pas, R., van Schaik, L.G. (2014). “Democratizing the World Health Organization”. Public Health, 128(2), pp. 195-201.

Van der Zwan, N. (2014). "Making Sense of Financialization”. Socio-Economic Review, 12(1), pp. 99-129.

WHO (2004). The Tobacco Industry Documents: What They Are, What They Tell Us and How to Search Them. Geneva, www.who.int/tobacco/publications/industry/ TI_manual_content.pdf?ua=1 (accessed: 15.08.2020).

WHO (2008). Evolution of the tobacco industry positions on addiction to nicotine. Geneva, apps.who.int/iris/bitstream/handle/10665/43988/9789241597265_eng.pdf?sequence $=1$ (accessed: 15.08.2020).

WHO (2009). Tobacco industry interference with tobacco control. Geneva, apps.who. int/iris/bitstream/handle/10665/83128/9789241597340_eng.pdf?sequence=1 (accessed: 2.09.2020).

WHO (2012). Technical resource for country implementation of the WHO Framework Convention on Tobacco Control Article 5.3. Geneva, https://www.who.int/tobacco/ publications/industry/technical_resource_article_5_3/en/(accessed: 15.08.2020).

WHO (2017). Integrated Cared for Older People. Guidelines on community-level interventions. Geneva, https://apps.who.int/iris/bitstream/handle/10665/258981/978924 1550109eng.pdf? sequence $=1$ (accessed: 15.08.2020). 
WHO (2018a). Report: Consultation on Tobacco Addictiveness Reduction Measures. Berlin, 15-16 May 2018, www.who.int/tobacco/publications/prod_regulation/meeting-reporttobacco-addictiveness-reduction-measures/en/ (accessed: 15.08.2020).

WHO (2018b). The Global Network for Age-friendly Cities and Communities: Looking back over the last decade, looking forward to the next. Geneva, https://apps.who.int/ iris/bitstream/handle/10665/278979/WHO-FWC-ALC-18.4-eng.pdf? sequence =1 (accessed: 7.09.2020).

WHO (2019a). WHO Report on the Global Tobacco Epidemic. Geneva, apps.who. int/iris/bitstream/handle/10665/326043/9789241516204-eng.pdf?ua=1 (accessed: 7.09.2020).

WHO (2019b). WHO global report on trends in prevalence of tobacco use 2000-2025. Geneva, www.who.int/publications-detail/who-global-report-on-trends-in-prevalence-of-tobacco-use-2000-2025-third-edition (accessed: 2.09.2020).

WHO (2019c). Towards an Age-friendly World. Geneva, https:/www.who.int/ageing/ age-friendly-world/en/ (accessed: 15.08.2020).

Williams, S.J., Calnan, M. (1996). “The 'Limits' of Medicalization? Modern Medicine and the Lay Populace in 'Late' Modernity". Social Science and Medicine, 42(12), pp. 1609-1620.

Zola, I.K. (1973). "Pathways to Doctor - from Person to Patient". Social Science and Medicine, 7(9), pp. 677-689. 


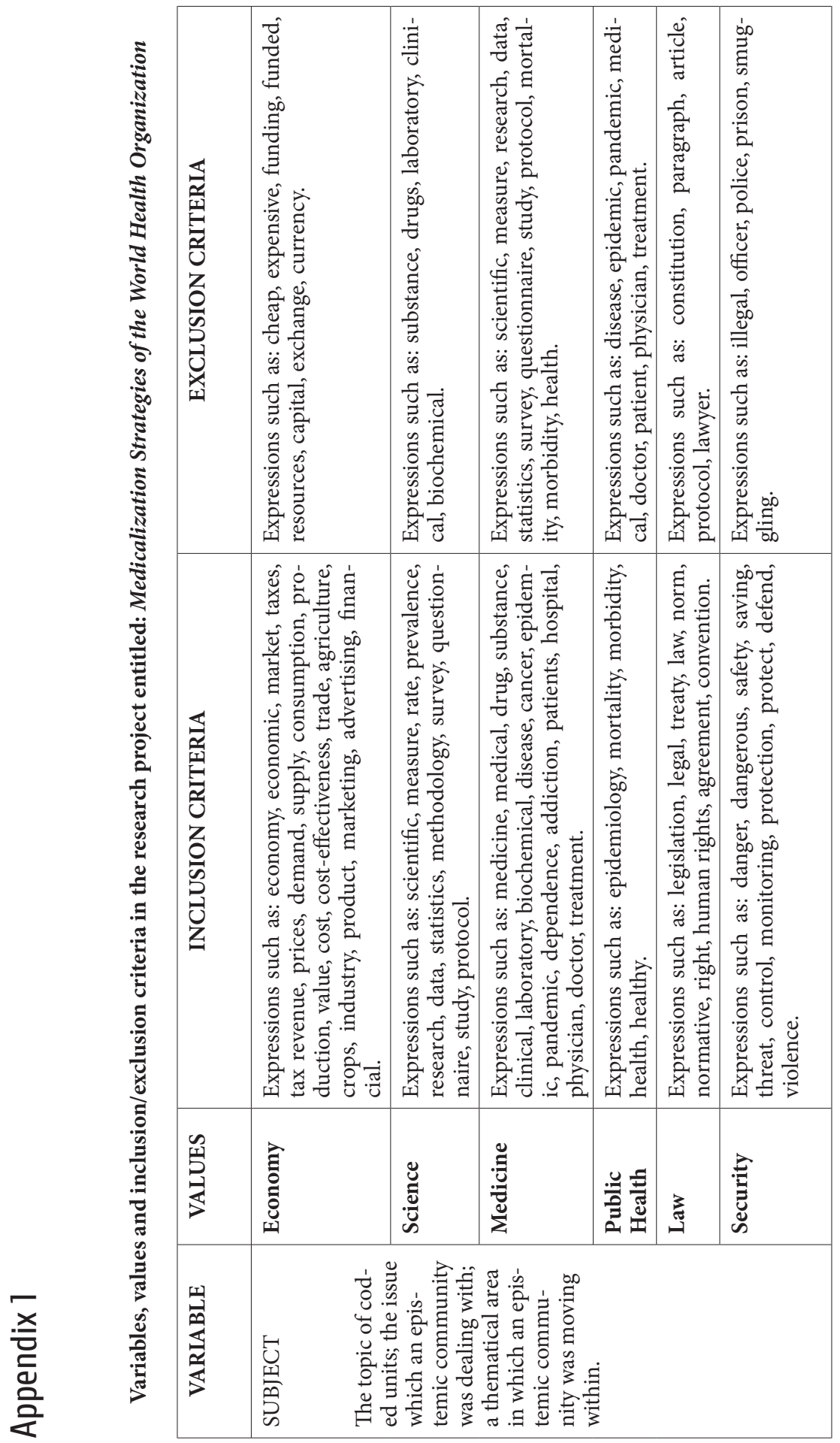




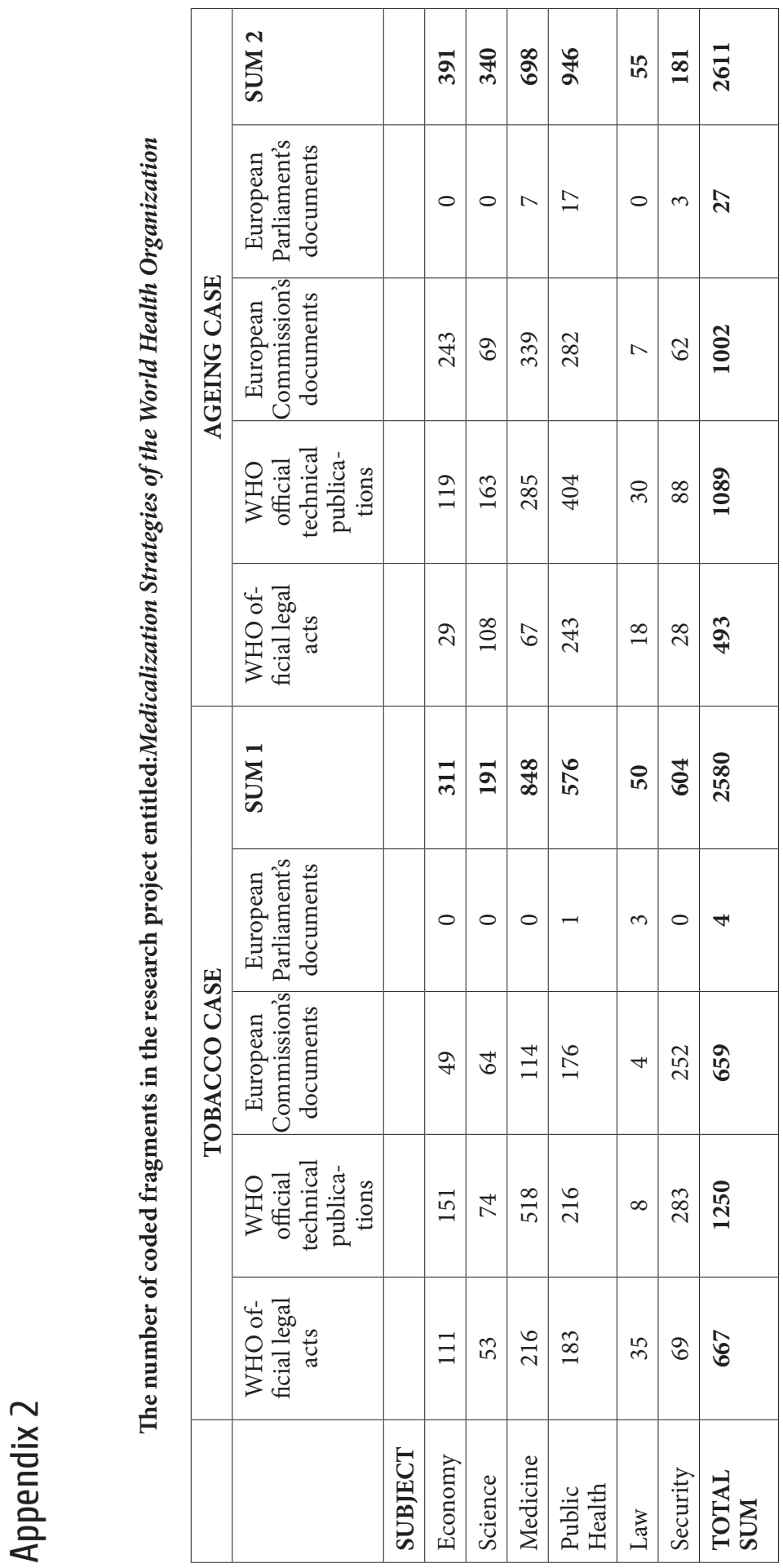


